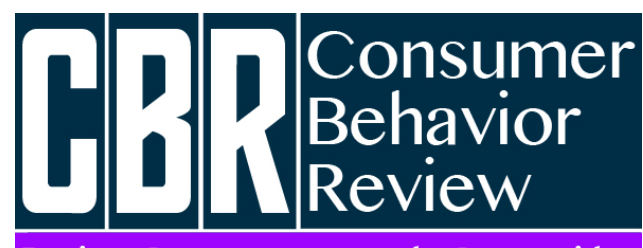

Revista Comportamento do Consumidor
Melo, D. L., \& Araujo, F. F. (2021). Significados do Almoço Completo Italiano: Articulações de consumo e cultura em uma experiência gastronômica em São Paulo.

Consumer Behavior Review, 5(1), 89-109.
ISSN: 2526-7884

Editor: Prof. Dr. Marconi Freitas da Costa

E-mail: cbr@ufpe.br
Avaliação: Double blind review

Recebido: 13 de Agosto, 2020

Aceito: 30 de Novembro, 2020

\title{
SIGNIFICADOS DO ALMOÇO COMPLETO ITALIANO: ARTICULAÇÕES DE CONSUMO E CULTURA EM UMA EXPERIÊNCIA GASTRONÔMICA EM SÃO PAULO
}

Meanings of Italian Complete Lunch: Articulations of consumption and culture in a gastronomic experience in São Paulo

\author{
Diogo Lannes Melo ${ }^{1}$ \\ ORCID: https://orcid.org/0000-0001-6053-394X \\ E-mail: diogolannes@gmail.com \\ Fábio Francisco de Araujo ${ }^{1}$ \\ ORCID: https://orcid.org/0000-0002-5581-5640 \\ E-mail: fabiofdearaujo@gmail.com
}

${ }^{1}$ Instituto de Nutrição Josué de Castro da Universidade Federal do Rio de Janeiro, Rio de janeiro, Brasil

\section{Resumo}

Este estudo aborda o tema das significações presentes nos rituais de consumo da gastronomia italiana e da cultura alimentar. Observa-se que as motivações para o consumo da gastronomia italiana podem englobar objetivos distintos, como a tentativa de resgate cultural, nostalgia e influências familiares, curiosidade e busca hedônica por experiências agradáveis no âmbito da alimentação. 0 presente trabalho propõe-se a analisar os significados atribuídos ao consumo do almoço italiano completo (pranzo completo) por um grupo de estudantes de italiano e sua docente

\begin{abstract}
This study addresses the theme of meanings present in the consumption rituals of Italian gastronomy and food culture. It is observed that motivations for the consumption of Italian gastronomy can encompass different objectives, such as the attempt at cultural rescue, nostalgia and family influences, curiosity and hedonic seek for pleasant experiences in the context of feeding. The present work proposes to analyze the meanings attributed to consumption of a complete Italian lunch (pranzo completo) by a group of Italian students and their teacher
\end{abstract}


residentes na cidade de São Paulo. Realizou-se uma etnografia composta de observação participante, entrevista pessoal e análise de dados. Os resultados apontaram cinco categorias nativas emergentes dos dados: a cultura do consumo alimentar italiana; hospitalidade e sociabilidade no encontro à mesa; trocas interacionais no encontro à mesa; o simbolismo presente nos rituais representativos da gastronomia italiana; (re)construção da identidade cultural italiana por meio de experiências de consumo no contexto gastronômico. Percebeu-se que o almoço, na perspectiva da professora organizadora, era uma maneira de construir e preservar o self italiano. Em relação aos alunos, embora possuíssem valores individuais, o almoço evidenciou a formação de um subgrupo entusiasta pela vivência da cultura italiana por meio das experiências de imersão proporcionadas pelo encontro.

Palavras-chave: Significados do Consumo; Pranzo Completo; Cultura Italiana; Identidades Sociais. residing in São Paulo city. An ethnography composed of participant observation, personal interview and data analysis was carried out. The results showed five native categories emerging from the data: the culture of Italian food consumption; hospitality and sociability when meeting at the table; interactional exchanges at the table; the symbolism present in representative rituals of Italian gastronomy; (re) construction of the Italian cultural identity through consumption experiences in the gastronomic context. It was realized that lunch, from the perspective of organizing teacher, was a way to build and preserve the Italian self. In relation to the students, although they had individual values, lunch showed the formation of a subgroup enthusiastic about concrete living of Italian culture through immersion experiences provided by the meeting.

Keywords: Consumption Meanings; Pranzo Completo; Italian Culture; Social Identities.

\section{INTRODUÇÃO}

As motivações para o consumo da comida italiana podem englobar objetivos distintos, desde a tentativa de resgate cultural, nostalgia e influências familiares, até a curiosidade e a busca hedônica por experiências agradáveis. As práticas de consumo dos indivíduos acontecem por significações particulares e coletivas que, ao atender tais objetivos, evidenciam características do comportamento social de quem consome e o processo de identificação pessoal (Ahuvia, 2005).

No Brasil, a gastronomia italiana está presente em locais caracterizados pela formação de colônias de imigrantes, tais como cidades do Rio Grande do Sul, Santa Catarina, São Paulo e Espírito Santo, locais em que essa gastronomia assume importante papel de identificação e herança cultural (Peres, 2011; Collaço, 2012; Zanelato \& Da Mota, 2014; Machado, Menasche, \& Salamoni, 2015; Perini \& Gastal, 2017). Em decorrência desse fenômeno imigratório, destaca-se a presença da gastronomia italiana no ambiente de serviços, no qual os aspectos da representação cultural se somam à aceitação do público e à hospitalidade (Leoni, 2016).

0 consumo alimentar é capaz de revelar características da identidade individual ou coletiva. A discussão sobre as influências das práticas de alimentação na construção identitária é levantada em diversos contextos atualmente, tais como motivações ideológicas ou ativismo (Portilho, 2020); saúde e estética (Jayne et al., 2018; Sauerbronn, Teixeira \& Lodi, 2019); estilo de vida (Yen, Cappellini, Wang \& Nguyen, 2018; Molinario et al., 2020); e, especialmente, etnicidade (Moffat, Mohammed \& Newbold, 2017; Corrêa, Cardoso \& Silva, 2020; Rustomgy \& Bastos, 2020). Em comum, esses trabalhos apontam a alimentação como sistema simbólico que, em suas particularidades, reflete identidades sociais (Maciel, 2001; Castro, Maciel \& Maciel, 2016).

Alguns estudos recentes abordam a formação de uma identidade italiana por indivíduos brasileiros a partir da alimentação. Mostram que a comida e os rituais durante as práticas de consumo são importantes elementos identitários do povo italiano preservados ou resgatados pelos brasileiros 
em suas manifestações culturais (Benazzi, 2015; Vendrame, 2018; Manfio, 2019). Entretanto, a maioria destes trabalhos concentra sua investigação nas colônias italianas rurais ou urbanas. Fato que revela a oportunidade e a necessidade de se conhecer melhor as características do comportamento de consumo da gastronomia italiana em nosso país quando este ocorre em outros contextos de imersão cultural.

0 presente trabalho propõe-se a analisar os significados atribuídos por um grupo de estudantes de italiano ao almoço completo (pranzo completo), organizado por sua docente, na cidade de São Paulo. Esta atividade ocorre anualmente entre os participantes como forma de imersão na língua e na cultura a partir da experiência gastronômica. 0 estudo tem por objetivo investigar as representações de consumo do pranzo completo quando realizado no contexto de ensino brasileiro, procurando investigar as articulações do consumo e da cultura a partir dos significados atribuídos a esta prática alimentar. Nesse sentido, procura-se, nesta pesquisa, responder a seguinte questão: Quais os significados atribuídos à experiência de consumo do almoço completo italiano são incorporados por brasileiros que a vivenciam?

Para tanto, antes se faz necessário um aprofundamento acerca das características da gastronomia italiana e seu consumo no Brasil, bem como sobre as relações entre consumo, cultura e identidade.

\section{REVISÃO DE LITERATURA}

\section{Breve histórico da gastronomia italiana e o consumo no Brasil}

As origens da gastronomia da Itália remontam ao período da Idade Média, quando, devido às características geográficas da península itálica, as populações estabelecidas próximo ao Mediterrâneo vivenciaram as primeiras trocas culturais com os povos vindos de outras regiões e posteriormente contribuíram para a formação das cidades-estado (Bertonha, 2013; Montanari, 2013a; Rabbiosi, 2019). Sert (2017) aponta as várias influências na formação da cultura alimentar italiana provenientes das trocas com gregos, fenícios, germânicos, árabes, hispânicos e franceses.

A unificação da Itália é considerada tardia no contexto do continente europeu, de forma que a consolidação da identidade da cozinha italiana antecede à formação da nação. Esta cozinha é definida, a princípio, como um conjunto de cozinhas regionais mais antigas (Capatti \& Montanari, 2003; Albala, 2004; Bacin \& Azevedo, 2012).

Concomitante ao processo de unificação italiana, o contexto econômico e político trouxe condições socioeconômicas controversas às regiões do país até o período das grandes guerras (Helstosky, 2004; Sert, 2017). O intervalo que compreende a unificação e o pós-guerra foi marcado por uma diáspora das classes trabalhadoras urbanas e rurais, cujo fluxo migratório para outras regiões da Europa, América do Norte e América do Sul configuraria o principal meio de disseminação da gastronomia italiana pelo mundo (Cinotto, 2019).

O fluxo migratório da diáspora italiana ao Brasil teve seu auge no final do século XIX e início do século XX (Oliveira, 2006; Silva \& Confrontin, 2015; De Ruggiero, 2018). Santos e Zanini (2007) destacam que a chegada dos imigrantes foi um marco na mudança dos hábitos e da cultura alimentar após a formação das primeiras colônias. Inicialmente, eram italianos que emigraram do norte do país, estabelecendo-se em cidades das regiões sul e sudeste do Brasil, sendo posterior a chegada dos imigrantes provenientes do sul da Itália (Collaço, 2012; Perini \& Gastal, 2017).

Vendrame (2018) aponta a alimentação como ponto central das dinâmicas de organização familiar, trabalho, confraternização e manifestação cultural. Assim, o consumo da gastronomia italiana no Brasil se deu, em primeiro lugar, nas casas dos imigrantes de forma cotidiana ou em festividades de grande importância simbólica (Fantineli \& Becker, 2011). Nos rituais festivos, observa-se a manifestação da identidade italiana por meio do forte apego ao consumo alimentar étnico, como o que ocorre na Festa da Uva e na Festa de Sant'Ana no sul do país (Santos \& Zanini, 2008; Machado et al., 2015).

O hibridismo cultural que se seguiu, com o intercâmbio cultural entre brasileiros e italianos, popularizou alguns alimentos e pratos provenientes da cultura italiana por todo o território nacional, tais como a pizza, a polenta, o vinho, o risoto e as massas (Oliveira, 2006). 
Apesar do contexto da alimentação como manutenção da cultura, a possibilidade de gerar renda com a culinária étnica permitiu que surgissem estabelecimentos familiares que serviam pratos típicos na intenção de atrair os colonos da classe trabalhadora e os entusiastas dessa cultura alimentar (Fonseca \& Camargo, 2013; De Ruggiero, 2018). Esse foi o ponto de partida para o marco da multiplicação das cantinas, configurando o início do consumo da gastronomia italiana no ambiente de serviços no Brasil (Collaço, 2012; Leoni, 2016).

Tanto as práticas de consumo cotidianas e caseiras quanto aquelas que ocorrem nos ambientes de serviço ou em rituais festivos específicos carregam significações que aproximam o fenômeno do consumo aos elementos constituintes da cultura de um povo.

\section{Consumo e Cultura}

A Teoria de Cultura do Consumo - Consumer Culture Theory (CCT), a qual este estudo se filia, surge como campo de estudo dedicado à análise do comportamento do consumidor, que se propõe a descrever os relacionamentos dinâmicos entre as ações de consumo, o simbolismo envolvido e o contexto mercadológico em que se inserem (Arnould \& Thompson, 2005). Os autores realizaram uma revisão dos trabalhos que trataram dos aspectos sociocultural, simbólico e ideológico do consumo. A partir dessa revisão, um campo de conhecimento se abre para a investigação dos comportamentos dos indivíduos quando as práticas de consumo são refletidas pelo contexto cultural e a maneira como o mercado se adapta e responde a tais tendências. À vista disso, considera-se que o consumo está contextualizado com a concepção de cultura e de sociedade em que os indivíduos fazem parte, assim como suas práticas de consumo estão em conformidade com as crenças, valores e sentimentos que carregam consigo (Araujo, Turano \& Vieira, 2019). As escolhas adotadas pelo consumidor, para Chakravarti e Janiszewski (2003), são resultado da aplicação dos valores aprendidos e compartilhados em sociedade dentro de sua realidade mesmo que ocorram de forma inconsciente.

Holt (2002), em um estudo que ganhou ampla visibilidade entre os acadêmicos do assunto, aponta que nas últimas quatro décadas o fenômeno do consumo é tratado como ponto de construção, reconstrução, modificações e preservação das identidades sociais dos indivíduos. Para isso, existem artifícios comuns que dialogam com a significação atribuída a produtos e atividades presentes nas comunidades (Joseph \& Southcott, 2019). Bourdieu (1979) destacara o poder de distinção social dos hábitos de compra, refletidos nos processos de formação identitária que podem criar grupos de classificação heterogênea. A sociedade em que se encontram os consumidores influencia na definição de significados simbólicos atribuídos a determinados objetos, assim como às práticas de consumo que são compartilhadas (Araujo \& Rocha, 2019, Araujo et al., 2020).

Em seu clássico artigo, Belk (1988) estuda a influência do consumo no processo de construção identitária e cria o conceito de "eu-estendido" (extended self). 0 autor elucida os valores simbólicos presentes no comportamento dos consumidores e em suas posses, que configuram para eles uma espécie de representação fiel e individual de suas essências, ou seja, seu "eu-social" (self). Para Jenkins (2014), que parte para uma abordagem mais sociológica desta temática, a construção da identidade pode ser realizada de forma individual ou coletiva, com processos comparativos entre pessoas e objetos nas duas circunstâncias. Ainda assim, a construção individual é baseada nas diferenças que individualizam as pessoas, ao passo que a construção coletiva está baseada nas semelhanças que aproximam as pessoas em grupos que possuem uma identidade social comum. Ahuvia (2005) parte do pressuposto de que a identidade é construída de um modo ativo pelos indivíduos. Esse processo vai além das relações com as posses, pois dizem respeito às relações de afetividade dos indivíduos com bens e atividades com que estes se identificam.

Seja individual ou coletivamente, o processo identitário passa por práticas de consumo que denotam a tentativa de adequar-se, sentir-se representado ou inserido em um estilo de vida, uma aspiração social ou no compartilhamento de valores simbólicos. Sendo assim, um grupo social que representa esses valores pode servir de referência para a formação da identidade. 


\section{Influência dos grupos de referência no comportamento de consumo}

Um grupo de referência pode se tratar de um ou mais indivíduos, sejam eles reais ou fictícios, que possuem uma capacidade relevante de moldar comportamentos de outras pessoas, sobretudo em suas práticas de consumo e decisões de compra (Solomon, 2016).

Sobre a influência do grupo de referência no comportamento do consumidor, Schouten e McAlexander (1995) realizaram uma pesquisa etnográfica sobre um subgrupo de consumo dos motociclistas norte-americanos. 0 estudo articula consumo, cultura e comportamento humano, tendo se dedicado a observar a influência do grupo de referência a partir das práticas de consumo de seus membros. 0 subgrupo de consumo estudado foi o dos proprietários de motocicletas Harley-Davidson, bikers conhecidos como Harley Owners Group (HOG). Para os autores, há um forte o sentimento de união e fraternidade, que permitem gerar consumo paralelo com a marca, como tatuagens, camisas, canecas, para sinalizar o estilo de vida do subgrupo e identificar os integrantes transmitindo valores de pertencimento.

Um estudo conduzido em comportamento do consumidor e alimentação, fortemente relacionado pela influência do grupo de referência foi realizado por McFerran, Dahl, Fitzsimons e Morales (2010). A pesquisa se dedicou a compreender as escolhas alimentares de jovens universitários, avaliando o impacto dos grupos de referência sobre o comportamento de consumo. Os autores realizaram três experimentos em uma Universidade dos EUA, que consistiam na investigação da influência que os biótipos obeso e magro, entre os componentes do subgrupo, exerceriam sobre o padrão de consumo de alimentos dos demais membros. Percebeu-se que o biótipo do corpo pode servir como referência de consumo nos grupos, afetando a escolha da porção de alimentos, influenciando, portanto, o comportamento de consumo alimentar dos demais indivíduos.

No Brasil, Araujo, Bitar, Santos, Baião e Silva (2019) realizaram uma etnografia no Rio de Janeiro sobre o evento da tradicional feijoada da escola de samba Portela, mostrando o simbolismo presente no ritual de consumo em grupo da alimentação associada ao samba. Os autores observaram de forma participativa o evento e puderam verificar o processo de produção de sentido nas práticas de consumo alimentar em ambiente de sociabilidade. Os frequentadores compõem um subgrupo que partilha dos mesmos valores. As figuras mais emblemáticas da escola de samba constituem o grupo de referência, a chamada Velha Guarda da Portela. Nos resultados, os autores mostram que tal grupo de referência é responsável por transmitir as tradições da escola e orientar a dinâmica da festividade estabelecendo suas diretrizes.

0 embasamento trazido nesta seção, junto às anteriores, sugere que a investigação das práticas de consumo alimentar do grupo de estudantes de italiano e de sua docente organizadora do evento pode gerar informações acerca das significações do consumo da gastronomia italiana e os processos identitários dos indivíduos inseridos na experiência. A seção seguinte trata do método utilizado a fim de realizar a investigação proposta nos objetivos deste estudo.

\section{MÉTODO}

Este trabalho se filia ao paradigma interpretativo, que, em comportamento do consumidor, é considerado adequado para compreensão de como o indivíduo interage e constrói significados com os objetos e as práticas de consumo, buscando traduzir a realidade construída (Hirschman \& Holbrook, 1992). O paradigma interpretativista consiste na elaboração, por parte do pesquisador, de uma descrição profunda e uma interpretação consistente em relação aos fenômenos sociais estudados (Brown, 1997). Para realização da análise proposta neste estudo, optou-se por empreender uma pesquisa exploratória e adotar métodos advindos da etnografia, notadamente a observação participante e entrevista em profundidade. Pretendeu-se, assim, contribuir para o aprofundamento do conhecimento sobre a relação do consumo e cultura, tendo como foco de estudo as práticas gastronômicas de origem italiana em uma cidade brasileira.

Realizou-se uma etnografia, com observação, entrevistas e análise de dados (Tureta \& Alcadipani, 2011). A coleta de dados foi basicamente dividida em duas etapas. A primeira ocorreu por meio de uma observação participante de uma experiência de almoço completo (pranzo completo) italiano em um evento oferecido para estudantes do curso de língua, composto majoritariamente por 
jovens universitários de origem ítalo-brasileira. A segunda etapa ocorreu por meio da entrevista em profundidade realizada com a idealizadora do evento, uma professora de italiano que articula o ensino da língua italiana com a cultura e, em especial, promovendo um destaque à experiência da interação das relações sociais com a alimentação.

A observação participante é aquela em que o pesquisador ingressa no grupo estudado como se fosse membro, procurando participar das atividades que são desempenhadas pelo grupo em questão (Stacey, 1977). Essa etapa ocorreu no dia 26 de outubro de 2019. Os alunos eram, em grande parte, do curso de línguas em que a docente leciona italiano. Entretanto, também a idealizadora do almoço italiano convidou alguns de seus alunos que praticam aulas particulares. Cabe pontuar que o evento não tem relação formal com o curso de italiano, mas é uma proposta didático-pedagógica da docente oferecida aos alunos interessados, que defende que o processo de aprendizagem de uma língua não pode ocorrer fora do contexto cultural. Reuniram-se treze pessoas para o encontro. Além do pesquisador, estavam a anfitriã e seu marido, nove alunos e um convidado do casal. Ao final da observação participante, gerou-se um acervo de fotografias e vídeos, além dos registros do pesquisador no diário de campo. Pontua-se ainda que as conversas informais com os participantes contribuíram também para elaboração do roteiro de entrevista formal, realizada posteriormente.

A segunda etapa da coleta de dados consistiu na entrevista em profundidade com a docente de italiano organizadora do encontro. A entrevista pessoal com sujeitos mergulhados no fenômeno investigado e, portanto, integrados à realidade cultural que se estuda, é um dos métodos mais empregados na pesquisa etnográfica (Spradley, 1979) e, segundo McCracken (1988), esta técnica deve ser considerada essencial para os estudos de consumo porque permite chegar mais próximo do universo mental dos indivíduos entrevistados. Seidman (1998) ensina que o objetivo de uma entrevista em profundidade é mergulhar na experiência vivida pelo informante para entender o processo de produção de sentidos e assim chegar aos significados socialmente atribuídos a partir da visão das pessoas inseridas no fenômeno investigado.

Nesse sentido, para realização da entrevista foi construído um roteiro semiestruturado, composto por perguntas abertas e flexíveis para aprofundar a compreensão da experiência. Esse procedimento seguiu os protocolos de Strauss e Corbin (2008). A entrevista foi realizada no dia 27 de outubro de 2019 presencialmente pelo pesquisador na cidade de São Paulo, com duração de cerca de 1 (uma) hora e 30 (trinta) minutos, tendo sido integralmente gravada e transcrita para análise.

Reunidos os dados coletados, seguiu-se uma análise sistemática dos dados por meio de técnicas de análise de conteúdo, procurando identificar as percepções e os significados atribuídos à experiência do pranzo completo. A leitura exigiu um exercício denso, gerando uma "codificação" de categorias iniciais e genéricas. Os dados foram analisados progressivamente à medida que eram organizados, utilizando a técnica de comparação constante descrita por Strauss e Corbin (2008), que buscava a extração de significados preliminares para o encaminhamento de uma análise posterior mais aprofundada. Ao final desta última leitura foi possível reconhecer padrões nos discursos dos participantes e da entrevistada, fazendo emergir as categorias estruturantes que serão apresentados no capítulo referente aos resultados deste trabalho.

\section{RESULTADOS}

\section{Contextualização do evento}

Esta seção aborda as informações que possibilitam uma inserção mais adequada ao microcosmo estudado pelo pesquisador e o detalhamento do contexto do almoço. Com a finalidade de preservar a identidade dos participantes, foram escolhidos nomes fictícios para representá-los neste estudo.

A organizadora do evento, Marta, é professora de italiano há mais de 30 anos na cidade de São Paulo. Por ser descende de uma família de italianos, sempre esteve em contato com os aspectos da cultura desse país, sobretudo música e culinária, pela influência de sua avó materna. A inserção desde a infância nos costumes italianos, somada à vocação para o ensino e as sugestões paternas, motivaram Marta a seguir a profissão de professora de idioma. Atualmente, ministra aulas particulares de italiano, em sua residência ou nas de seus alunos, bem como em um curso de idiomas da capital paulista. A 
reunião para celebração do pranzo completo acontece há quase 15 anos e é iniciativa da própria professora, não fomentada pelo curso onde leciona. Assim, o convite se estende a um público limitado e selecionado pela organizadora. Os alunos, em maioria, possuem situação financeira que os enquadra em classes A e B, sejam eles de aulas particulares ou matriculados no curso de idiomas. As aulas de italiano oferecidas são procuradas, em maior parte, por estudantes universitários que possuem ascendência familiar italiana. Esses estudantes também procuram aprender italiano porque desejam aproveitar a oportunidade de períodos de intercâmbio no país; ou mesmo aqueles que já vivenciaram essa oportunidade oferecida pela universidade e desejam se aprimorar no idioma. A proposta do evento organizado por Marta atrai os alunos mais jovens, normalmente interessados em uma didática de ensino mais intimista e menos ortodoxa.

0 evento de almoço acontece anualmente na residência de Marta. Um apartamento localizado na área residencial de um bairro de classe média-alta na cidade de São Paulo, onde os alunos são recebidos por ela e seu marido Tadeu, colaborador do evento, responsável principalmente pelo apoio nas preparações culinárias e no serviço ao longo do encontro. 0 local possui uma ampla sala, dividida em dois ambientes, estar e jantar, em que foi possível alocar todos os convidados. As bebidas foram dispostas em uma bancada próxima à mesa de almoço. Uma mesa de centro na sala de estar também foi utilizada para serviço de algumas etapas da refeição. Apesar do espaço ser suficiente para acomodar todos os convidados, a mesa principal não possuía o número certo de lugares, fato que impedia que todas as etapas fossem servidas no mesmo espaço ininterruptamente, porém proporcionava o deslocamento dos convidados entre elas. É importante ressaltar que a confraternização compõe um tipo de aula prática de conversação em um contexto específico do ensino da língua italiana. Além disso, em vários momentos houve pausas para explicações e demonstrações com auxílio de material didático, o que sustentava a característica didática junto ao plano de confraternização e imersão cultural.

A proposta de reprodução de um almoço completo italiano contemplava os ensinamentos sobre o comportamento à mesa dos italianos, sua cultura alimentar e os aspectos da hospitalidade italiana, além da prática de conversação do idioma. Apesar da tentativa de manter a fidelidade às receitas do país, considerando o intuito da anfitriã de repassar aquilo que ela entende por cultura alimentar italiana, em algumas etapas do almoço houve algumas adaptações que aparecerão nas seções seguintes.

A seguir, é apresentado um quadro que lista os participantes do evento, exceto o pesquisador, bem como suas idades aproximadas, o papel no encontro (organizador, colaborador ou convidado), a relação com o idioma (alunos particulares ou do curso de idiomas), além das influências culturais que os aproximam da língua e do desejo de aprendê-la.

\begin{tabular}{|c|c|c|c|c|c|}
\hline Entrevistado & $\begin{array}{c}\text { Faixa } \\
\text { Etária }\end{array}$ & Sexo & $\begin{array}{c}\text { Participação } \\
\text { no evento }\end{array}$ & $\begin{array}{c}\text { Relação com o } \\
\text { idioma }\end{array}$ & Influência Cultural \\
\hline Marta & $50-55$ anos & Fem. & Organizadora & Professora & Família \\
\hline Tadeu & $55-60$ anos & Masc. & Colaborador & - & - \\
\hline Bruno & $20-25$ anos & Masc. & Convidado & Aluno Curso & Experiência no país \\
\hline Rafaela & $20-25$ anos & Fem. & Convidada & Aluna Curso & $\begin{array}{c}\text { Família/ Experiência no } \\
\text { país }\end{array}$ \\
\hline Marcelo & $20-25$ anos & Masc. & Convidado & Aluno Curso & Família \\
\hline Lucas & $20-25$ anos & Masc. & Convidado & Aluno Curso & Família \\
\hline Heitor & $20-25$ anos & Masc. & Convidado & Aluno Curso & Família \\
\hline Gabriel & $20-25$ anos & Masc. & Convidado & Aluno Curso & Família \\
\hline Celso & $30-35$ anos & Masc. & Convidado & Aluno Particular & Profissão \\
\hline Pedro & $25-30$ anos & Masc. & Convidado & Aluno Particular & $\begin{array}{c}\text { Família/ Experiência no } \\
\text { país }\end{array}$ \\
\hline João & $35-40$ anos & Masc. & Convidado & Aluno Particular & Experiência no país \\
\hline Júlio & $35-40$ anos & Masc. & Convidado & - & - \\
\hline
\end{tabular}

Fonte: Elaboração dos autores.

Quadro 1: Participantes do almoço completo 
O quadro 1 mostra que a maior parte dos alunos convidados estão matriculados no curso de idiomas. Estes possuem a menor média de idade entre os presentes. Percebe-se que, dentre os jovens universitários do curso, o interesse pelo ensino da língua ocorre por conta de influências culturais familiares, com o objetivo de futuramente experimentar a vivência na Itália por meio da oportunidade de intercâmbio pela universidade. Dos convidados, apenas um deles buscou o curso por motivações que não estavam relacionadas às influências familiares ou de experiência na Itália, sendo um aluno particular por motivos de demanda profissional.

\section{O pranzo completo}

0 almoço, chamado pela anfitriã de "spaghettata", procurou remontar a estrutura típica da tradição do pranzo italiano completo. 0 evento iniciou às $12 \mathrm{~h}$ e se concluiu às $18 \mathrm{~h} 30$, totalizando seis horas e meia de encontro. A cada etapa, são destacados elementos culturais da culinária, geografia, história e identidade social italiana. Trata-se de uma proposta de imersão cultural, que busca articular língua, culinária e relação social em torno da comida. 0 almoço, mesclando pratos típicos das culinárias do norte, centro e do sul da Itália, busca retratar uma ocasião de reunião familiar ou de amizade em datas comemorativas, confraternizações, casamentos, aniversários ou feriados.

0 almoço teve início pontualmente às $12 \mathrm{~h}$, ainda que nem todos os convidados estivessem presentes no horário marcado. Uma mesa de centro localizada na sala de estar estava guarnecida com pequenas porções de petiscos. Essa forma de entrada foi apresentada pela anfitriã como "apri pranzo". Essas preparações eram consumidas com as mãos enquanto o vinho era servido aos convidados conforme iam chegando.

No evento estudado, os alunos convidados eram responsáveis por trazerem os vinhos como uma forma de ingresso estabelecida pela professora promotora do evento. Segundo ela, a responsabilidade de comprar o vinho foi uma forma de ensinar os alunos sobre os costumes italianos e inseri-los na prática da escolha e degustação de vinhos, algo típico da cultura do país. 0 apri pranzo também funciona como uma forma de acolhimento aos convidados atrasados. Ela esclarece que os italianos prezam pela pontualidade nos encontros sociais:

"Basicamente, a gente começa falando em "apri pranzo" (...) para começar a conversar, começar a beber. Na verdade, para dar tempo aos retardatários. (...). Eu digo para começarmos $12 \mathrm{~h}$ e não a partir de $12 \mathrm{~h} .(. .$.$) .$

Eu falo para os alunos: sábado, 12:00, senão eles chegam 14h. Então eu falo: Se você chegar $14 \mathrm{~h}, 15 \mathrm{~h}$, você vai perder o antepasto, vai perder isso e aquilo. Porque eu vou seguir a ordem".

Posteriormente, por volta de 12:30, já se reuniam 10 pessoas das 13 que participariam do evento e a primeira etapa típica de um "pranzo completo" italiano foi servida. A etapa de antipasti caracteriza-se pelo serviço de entradas em pequenas porções que podem ser consumidas à mesa ou de forma volante. No almoço, foram servidas duas opções: a primeira foi uma barqueta recheada com creme de aspargos e azeitonas; o segundo antepasto foi uma bruschetta com molho pesto genovês. Durante esta etapa, assim como nas seguintes, foi servido vinho aos presentes, que poderiam escolher entre tinto e rosé, ou água. É importante ressaltar que os próprios convidados se serviam, comportamento típico nas casas italianas, como indicou a professora durante a posterior entrevista em profundidade. É comum que as celebrações que envolvem um almoço completo nas casas italianas tenham um caráter mais informal, em que os comensais têm liberdade para servirem-se da maneira que lhes julgam mais confortável.

Às $13 \mathrm{~h}$ deu-se início à segunda etapa. Neste momento, os 13 participantes do encontro já se encontravam na casa da anfitriã. Chamada de primo piatto, caracterizou-se pela oferta de uma massa do tipo farfalle com duas opções de molho: pesto genovês e molho de tomate caseiro com ragu de linguiça. Assim, às $14 \mathrm{~h}$ se iniciou a terceira etapa do evento, chamada de secondo piatto. Foi servida uma torta de massa folhada e recheio de queijos, presunto e palmito. Como acompanhamentos duas opções: caponata siciliana de berinjela e peperonata (pimentões vermelhos, amarelos e alcaparras). Após, novamente os convidados são chamados à mesa, quando então houve uma breve explicação 
histórica sobre o prato, sua região de origem, e forma de preparo. 0 segundo prato teve duração de pouco mais de uma hora.

Um intervalo de mais de 30 minutos foi efetuado antes da etapa seguinte. Esse tempo é normalmente destinado às conversas, músicas, dança e confraternização que permite o início do processo de digestão e descanso para fase seguinte do almoço.

A quarta etapa, última com serviço de preparações empratadas, foi a sobremesa. Teve início às 15:30. Como trazido em comentário pela anfitriã, a pausa entre o segundo prato e a sobremesa comumente se prolonga até mais de uma hora. Nela, ocorre a mudança da bebida que antecede e acompanha, do vinho tinto para os espumantes, que permitem uma limpeza e frescor do paladar para receber as preparações doces. Entre as sobremesas servidas, estava o tiramisu, opção de sobremesa típica para os italianos.

Mais tarde, em torno das $17 \mathrm{~h}$, uma outra etapa com serviço de café e biscoitos, seguida de licores, aconteceu. Esta última etapa acontece em ritmo menos acelerado e demarca o processo de finalização e despedida do evento. Às 18:30 os últimos convidados se despediram e, então, deu-se por encerrado o pranzo completo.

Os intervalos entre as etapas não são uma condição obrigatória nos encontros familiares italianos em que ocorre o almoço completo. Em muitas ocasiões, os convidados se sentam à mesa e as etapas são servidas de maneira ininterrupta desde os antipasti até a sobremesa. Em função das adaptações no espaço de realização do almoço na casa de Marta, os convidados se alternavam à mesa, mudavam de lugares e circulavam entre a sala de almoço/jantar e a sala de estar, ações que proporcionavam intervalos para conversas e aumento da interação, além de permitir que a mesa fosse rearranjada para as etapas seguintes. Ademais, o grau de interação dos convidados e a ocorrência ou não dos intervalos entre as etapas influenciam a duração total de um almoço completo italiano, que pode ser inferior ou superior àquela do evento estudado.

\section{Categorias estruturantes emergentes dos dados}

A análise de conteúdo revelou a existência de cinco categorias estruturantes de significação atribuídas ao consumo do almoço completo italiano a partir da experiência do evento analisado. Essas categorias emergentes serão apresentadas a seguir.

\section{A cultura do consumo alimentar italiana}

Da lógica do modo de ingestão dos alimentos, em relação aos italianos, destaca-se o fato de se alimentarem em etapas definidas, em contraponto à maneira brasileira de se comer as preparações juntas no mesmo prato a partir de uma mesa posta com as diversas opções (Da Matta, 2004; Barbosa, 2007; Oliveira \& Casqueiro, 2008; Ferreira \& Magalhães, 2011).

0 pranzo completo italiano é dividido em pelo menos quatro etapas, as quais apresentam critérios culturalmente adotados pelos indivíduos que ali se inserem (Monteleone \& Dinnella, 2009; Silva \& Confortin, 2015; Jurado, 2016). Os antepastos ou entradas normalmente são preparações menores e mais simples, podendo conter ingredientes frios ou quentes, servidas empratadas à mesa ou de forma volante como finger food, que são pequenas porções que se pode comer com mão. Ao passo que a etapa subsequente, o primeiro prato (primo piatto), é essencialmente composto de uma massa ou risoto servido em prato fundo. Esta é uma condição respeitada como regra pelos italianos, que não servem outras opções diferentes. Varia-se apenas o tipo de massa, molho ou sabor do risoto. 0 único acompanhamento servido nessa etapa é uma porção de pão, utilizado para que seja possível degustar as sobras de molho ou caldo do primeiro prato. Em seguida, no segundo prato, etapa principal do pranzo completo, é servida uma carne, torta, peixe ou frutos do mar acompanhados dos contornos, que podem ser uma salada, compota ou legumes cozidos. 0 serviço é realizado em pratos rasos de maior diâmetro. Em ocasiões de comemoração em família ou datas festivas do calendário italiano, é possível que haja o serviço de uma etapa de queijos e frutas antes da sobremesa, em que são servidos os doces. Entretanto, em muitos casos, os italianos têm por hábito seguir para a etapa do café e finalizar com licores e digestivos. Os trabalhos de Monteleone e Dinnella (2009) e Parasecoli (2014) corroboram com a descrição dos pratos típicos e organização da refeição mencionadas nesta pesquisa. 
O discurso da anfitriã permitiu identificar aspectos da cultura alimentar italiana referentes ao tempo dedicado às refeições e suas respectivas etapas, além da viabilidade de se desfrutar o mesmo tipo de almoço no espaço de serviços. Considerando a absorção dessa prática de consumo como representativa da cultura italiana, o almoço completo também é oferecido em restaurantes do país. No espaço comercial, dada a questão do tempo de duração, algumas adaptações podem ser necessárias, como apontado na fala da professora Marta:

“Mas, quando se está em um restaurante, nem sempre se dispõe de todo esse tempo. (...). Geralmente, você já avisa o garçom que vai querer um primo, secondo com contorno [acompanhamento]. Na Itália, quando é um almoço em forma de serviço em restaurante, você pode pedir todos os pratos de uma vez só. Eles vão produzindo, vão ver que você acabou o primeiro prato e irão trazer o segundo. É mais rápido".

É importante destacar a atenção que a anfitriã direcionou à escolha das louças e a montagem do prato de massa. Segundo ela, os costumes relacionados ao modo de empratar e servir a comida nesse tipo de ocasião é um traço marcante da identidade cultural italiana. Essa prática permanece nas famílias descendentes espalhadas pelo mundo e, sobretudo, nas famílias que ainda residem na Itália. A forma de organização da mesa, por ser expressiva da representatividade cultural, também é comum aos restaurantes italianos.

"O primo é sempre uma massa ou risoto; o secondo é uma carne ou fruto do mar com contorno [acompanhamento]. (...). Lá os pratos (louça) vêm juntos na montagem da mesa, o fundo para o primo e o raso para o secondo (...). Geralmente são montados com a massa por baixo, o molho em cima e o queijo ralado em cima do molho, se for o caso. Aí se deixa que as pessoas misturem depois. Jamais se mistura antes, isso é 'profanação'! Se fizer isso, o macarrão chega tingido".

O conteúdo da entrevista e das observações do evento permitiram alcançar informações acerca da importância e da função das bebidas servidas no pranzo completo, que se mostram representativo da cultura alimentar italiana. Segundo Marta, os vinhos, principalmente tintos e espumantes, fazem parte das reuniões de almoço, bem como do cotidiano dos italianos adultos.

"O vinho exerce três funções nesse momento: [1 ${ }^{\mathrm{a}}$.] serve para abrir o apetite, [2 ${ }^{\mathrm{a}}$.] serve como uma forma de estender o intervalo para chegar dos demais convidados e, principalmente, [3a.] serve para deixar as pessoas mais alegres e mais à vontade para interagir com os demais (...)". "É como se diz por lá: 'Rosso va bene com Rosso'. O vinho tinto combina com molhos vermelhos, encorpados. E com o pesto, que é muito gorduroso. Então, os taninos vêm para quebrar um pouco isso".

"O prosecco é para dar uma 'lavadinha' (sic) na boca, dar uma estourada com as 'bolhinhas' (sic) entre as refeições... Como eu estava explicando, é como se esquecesse um pouco do que tinha comido e segue para uma outra etapa que é o doce".

“O café vem primeiro porque é quente, depois o licor. 0 café com 'biscoitinho' (sic) é para uma última conversa (...); o licor é para dizer o 'tchau”'.

Esses achados corroboram com os resultados da pesquisa de Sieri et al. (2002) que apontam no sentido de que a maior parte das bebidas alcóolicas consumidas pelos italianos, em que pese majoritariamente representada pelos vinhos, é degustada junto às refeições.

\section{Hospitalidade italiana e sociabilidade no encontro à mesa}

Os dados adquiridos permitiram identificar algumas características da hospitalidade familiar dos italianos, fazendo emergir de modo marcante aspectos dessa hospitalidade própria em torno da alimentação. A forma como os convidados foram recebidos à porta - e neste ponto inclui-se o próprio pesquisador - denotou esforço de aproximação da anfitriã em fazê-los se sentirem como se estivessem 
"em suas próprias casas", confraternizando com suas próprias famílias. Foi possível observar a ausência de uma pessoa destinada exclusivamente a servir os convidados. Alia-se a isso os constantes pedidos para que os participantes continuassem a beber e degustar as preparações, que resultaram em uma rápida percepção de acolhimento, proporcionando uma sensação de intimidade que parecia ser comum aos presentes.

Como destacado anteriormente, a etapa inicial do almoço, apri pranzo, constituiu o primeiro momento de integração entre os comensais. Nesse momento, um dos convidados teceu de forma discreta um comentário sobre o comportamento da anfitriã durante uma conversa informal com o pesquisador, registrada em caderno de campo:

"Ela é assim mesmo, quer que a gente coma e beba o tempo todo". (Depoimento do convidado Marcelo aos autores).

Ao longo do evento, foi perceptível o significado atribuído à refeição como forma de recebimento e compartilhamento, uma ocasião que permite a troca interacional entre as pessoas. Os trabalhos de Ahuvia (2005), Araujo, Tonini e Estrella (2018), Barbosa (2010), Camargo (2004), Lashley, Morrison e Randall (2004) e Boutaud (2011) destacam a importância do ato de se comer e beber em grupo. Seja na companhia de amigos ou de familiares, pois tais eventos se expressam como representativo de uma prática cultural que possui como elemento característico a hospitalidade. As reuniões entre familiares e amigos, normalmente mais calorosas, envolvem quase sempre o emprego de comidas tradicionais e que despertam o sentimento de nostalgia, amizade e acolhimento, em que se destacam as reuniões típicas italianas (Lashley, Morrison \& Randall, 2004).

Ao longo do encontro, conforme maior aproximação entre os alunos participantes, se fez notar um diálogo mais intimista quando estes começaram a compartilhar entre si relatos sobre experiências na Itália e suas relações com a cultura italiana. As relações mencionadas entre os convidados orbitaram em torno de ascendência familiar ou, em outros casos, do entusiasmo com aspectos da língua, culinária, estilo de vida, entre outros. 0 ambiente produzido pela organizadora também contribuía para familiaridade de um almoço típico italiano. Uma das convidadas dividiu com o grupo sua experiência de participação em um almoço na Itália durante sua estadia no país, destacando a grande semelhança com o evento estudado neste trabalho:

"Quando eu estive lá [Itália] também participei de um almoço de família em um domingo, na casa de um amigo italiano. E o almoço 'rolou' (sic) até a noite. Eu cheguei de manhã e só fui sair 20h... Eu não aguentava mais comer! Era muita comida e povo não parava de comer! Era bem parecido com que estamos vivendo agora aqui. Todo mundo bebendo vinho, conversando, aquela coisa bem de se sentir em casa mesmo". (Depoimento da convidada Rafaela aos demais participantes).

A comida e a refeição auxiliam na sociabilidade dos convivas e permitem a construção de novos significados acerca da reunião de almoço. Essas percepções que emergiram significativamente neste estudo vão ao encontro do que foi verificado no estudo Lynch (2005). Os resultados identificados tanto pelo autor quanto nesta pesquisa apontam "casa" como algo que vai além da dimensão estrutural física, adquirindo significados que giram em torno das esferas social, cultural, temporal, emocional e até pessoal. Do ponto de vista da anfitriã, a confraternização de almoço é motivo da reunião de pessoas em torno da alimentação e funciona como um canal de interação social de longa duração. Essa forma de confraternizar festiva, longa, integrativa e em torno a comida e da bebida, emerge como representativa da cultura italiana, indicando um aspecto característico e identificador.

"Não se fala 'sala de jantar', se fala 'sala de almoço', 'sala da pranzo'... A gente começou $12 \mathrm{~h}$. Normalmente, termina 19h, 20h. (Depoimento da organizadora do evento Marta em entrevista aos autores). 
No discurso da professora foi possível identificar que a comida é um elemento muito importante nas relações sociais italianas, como mostrado nos trechos abaixo retirado da entrevista com a organizadora do evento:

"Então, os alunos têm que estar preparados para entender a cultura italiana. (...) Reunir-se à mesa para um italiano é muito importante; estar com os amigos, conversar".

"A cozinha é a coisa que mais une os italianos. (...). A comida interage, a comida une".

A oferta de comida e bebida são relacionadas à satisfação pessoal de um anfitrião com o bemestar de seus convidados, além de agir como reforço da memória afetiva e nostálgica, características que aparecem como um elemento cultural que contribui para formação da identidade social italiana. Um trecho da entrevista sintetiza a convicção da anfitriã quanto à importância do pranzo completo em relação à sociabilidade:

"Cozinhar para os outros significa se doar. As pessoas retribuem isso vindo, comendo, elogiando. A comida é isso, é confraternização; para os italianos é confraternização".

Os significados emergentes nesta categoria se aproximam ao que é apresentado no estudo de Collaço (2012). A autora aponta que a fartura presente nas confraternizações de imigrantes italianos, bem como nas de seus descendentes, alimenta o sentimento de nostalgia e partilha entre os comensais, tendo a comida como expressão de paradigmas sociais, tais como identificação nacional, cultural e pessoal de descendentes de italianos que residem no Brasil.

\section{Trocas interacionais no encontro à mesa}

Ao observar o almoço completo, constatou-se uma evolução das interações entre os participantes da sua chegada até o encerramento do evento. A princípio, o comportamento dos convidados era um pouco mais contido, principalmente entre os últimos a chegar, mostrando-se mais confortáveis em conversar com a anfitriã apenas. As conversas iniciais aconteciam em volume mais baixo, com assuntos que denotavam reconhecimento do evento e dos convidados. Contudo, a oferta de vinho entre os participantes e a disposição dos assentos em volta da mesa de apri pranzo facilitavam a interação, além do ato social de beber e comer em companhia, que estimulou o contato e o compartilhamento entre os presentes. Montanari (2013b) esclarece que ao convidar pessoas para dividir uma refeição, o gesto transcende a dimensão funcional da alimentação e passar a assumir valor comunicativo, sendo absorvido pela dimensão social.

A cada taça de vinho e a cada etapa do almoço, as pessoas tornavam-se mais entusiasmadas, menos inseguras e despreocupadas, inclusive, para tentar conversar em italiano. A professora, em entrevista ao pesquisador, destacou a importância do vinho como "lubrificante social" e como "agente" de identificação com a cultura italiana, contribuindo, inclusive, para o direcionamento a um comportamento acalorado, com conversas mais descontraídas, em volume mais alto. Segundo ela, essas são características dos italianos em seus encontros familiares.

"O vinho é sincero. Ele alimenta todos os pensamentos e a vida flui mais fácil. Então, depois que eles [alunos] bebem, eles podem falar, podem errar". (Depoimento da organizadora do evento Marta em entrevista aos autores).

A discussão em torno das preparações do almoço se repetia a cada etapa, conforme as barreiras comunicativas eram vencidas de maneira descontraída. A organizadora detalhou em depoimento, posteriormente, que a comida é um dos assuntos favoritos dos italianos nas reuniões familiares e entre amigos, por vezes servindo como um aparato pacificador quando se exaltam em suas discussões. 
"Se você quer tentar colocar um pouquinho de paz em um ambiente, você fala assim: 'Ontem eu preparei um risoto, mas o brodo [caldo de legumes] não ficou legal'. (...). De uma hora para outra, todo mundo está dando palpite e todo mundo é amigo de novo".

A intenção é que a participação de seus alunos nesse evento seja um estímulo para trabalhar sua capacidade crítica e uma oportunidade de inseri-los na dinâmica em que a comida é tópico que inflama as conversas e desafia as pessoas a expressarem suas opiniões. De acordo com Sassateli (2019), a comida surge como foco da interação entre os italianos e como assunto cotidiano em suas reuniões, permitindo que as pessoas expressem sua identidade cultural.

\section{O simbolismo presente nos rituais representativos da gastronomia italiana}

A preservação da identidade italiana à mesa, seja na própria Itália, seja nos inúmeros locais marcados pela descendência italiana, resulta em rituais representativos de sua gastronomia, que apresentam, retratam e reproduzem valores simbólicos específicos (Parasecoli, 2019). Cabe mencionar que o apelo simbólico da gastronomia italiana não passou despercebido pelos acadêmicos do assunto, pois o simbolismo da promoção da cultura presente no ritual gastronômico do pranzo completo já é mencionado na pesquisa de Jurado (2016), que se dedicou a investigar os significados de refeições no México, Estados Unidos e Itália.

Na presente pesquisa, a refeição foi pensada para oportunizar como símbolo da expressão cultural italiana para conhecimento dos convidados. A arrumação da mesa de almoço, da mesa de petiscos e o vinho servido no almoço trazem à tona a preocupação de se reservar um espaço físico e metafórico para a introdução dos convivas no grupo fraterno, que teve como referência a professora anfitriã. Logo, o esforço empregado por ela na recepção de seus convidados se assemelha ao valor simbólico da figura materna que se doa aos seus próximos por meio da cozinha, muitas vezes representada na cultura italiana pela figura da mamma. Nessa perspectiva, esse aspecto é mencionado na narrativa da anfitriã:

"As pessoas começam a deixar de pensar tanto em si mesmas e pensam mais em dar um pouco ao outro. E a cozinha é isso, é a consequência disso (...)".

Os convidados, no papel de comensais, enveredam por uma incorporação de valores simbólicos atribuídos ao almoço em grupo. Enquanto alguns buscam um fortalecimento da identidade italiana que advém de suas histórias familiares, outros buscam uma inserção na cultura italiana a partir das significações presentes nos rituais gastronômicos, visando a construir uma bagagem que lhes será útil em um ingresso no país em futuro próximo. Havia, entre os convidados, até aqueles que a princípio procuraram apenas o aprendizado da língua, mas com o passar do tempo se tornaram adeptos da dinâmica de inserção por experiências culturais típicas fomentada pela professora e passaram a incorporar valores apreendidos nessas experiências. Esse fenômeno identificado nesta pesquisa remota o que Fischler (1995) já destacava sobre a capacidade de incorporação simbólica por meio dos rituais de alimentação.

A refeição surge ainda como espaço simbólico de diálogo, em que a partilha do alimento se configura como um momento de preparação para o estabelecimento de um diálogo mais sério ou para noticiar algo, seja bom ou ruim. Sobre este aspecto, apesar de não se ter observado neste evento do pranzo completo, a organizadora relata em entrevista um simbolismo presente no ato de cozinhar e dividir a refeição:

"A minha avó italiana dizia uma coisa: 'Se você tem que dar uma triste notícia ao seu marido, faça-o comer bem. Depois que ele comer bem, você dá a notícia'”.

Os simbolismos expressos em rituais de alimentação, na literatura de comportamento do consumidor, evidenciam a presença de subculturas de consumo consolidadas (Solomon, 2016). Os trabalhos de McCracken (1987) e (1988) são importantes exemplos que tratam das influências desses 
aspectos no comportamento de consumo. Além de reconhecer a importância das práticas de consumo para as bases culturais da sociedade contemporânea, o autor aponta que o simbolismo presente nesses rituais é capaz de fomentar as aspirações de consumo em decorrência da rede de significados que o produto ou serviço representa para os indivíduos.

\section{(Re)Construção da identidade cultural italiana por meio de experiências de consumo}

No caso do pranzo completo investigado nesta pesquisa, a identidade cultural coletiva dos italianos é trazida para a realidade da professora anfitriã e de seus alunos sob vários aspectos, dos quais se destaca a gastronomia, o consumo e a comensalidade. 0 consumo simbólico da cultura da Itália por meio da culinária permite que a anfitriã possa expressar sua "italianidade" e, portanto, construir, fortalecer e manter coesa a sua identidade individual. Para os alunos, o simbolismo presente na relação hedônica com a cultura italiana se dá com motivações individuais que se direcionam para um mesmo ponto. Os valores incorporados por cada participante somam-se na construção da identidade de um grupo caracterizado pelo entusiasmo na busca pela inserção no universo cultural dos italianos.

O esforço da manutenção dessa identidade por conta dos núcleos imigrantes e do reconhecimento pela sociedade à volta dialogam com as experiências vividas em festivais, comemorações em comunidade, em narrativas sobre a imigração e também no espaço gastronômico de serviços (Bacin \& Azevedo, 2012; Machado, Menasche \& Salamoni, 2015; Perini \& Gastal, 2017; Manfio, 2017).

Partindo do depoimento trazido pela idealizadora do evento estudado, é possível constatar que as manifestações culinárias emergem como um dos principais fatores a contribuir com a identidade cultural italiana fora da Itália, seja para seu fortalecimento, seja para seu reconhecimento, seja para a sensação de pertencimento. Abaixo, um trecho em que a entrevista retrata essa constatação:

"Já que não tiveram países colonizados por eles, com todos esses êxodos, os italianos foram se espalhando pelo mundo, mas tentaram sempre manter a própria cultura. (...) E uma das maneiras mais fortes de reviver o próprio país é com a comida".

Os participantes do evento, em conversas ao longo do almoço, indicaram que a culinária italiana estava presente em seu cotidiano de outras formas. Para alguns, por conta da ascendência familiar, outros ao consumir a cozinha da Itália em espaços de serviço. As diversas motivações que envolvem o consumo estão ligadas à construção identitária ao regular as relações sociais e desenvolver significações que advém do ato (Barbosa \& Campbell, 2006; Kotler \& Keller, 2012). Os dados colhidos sugerem que o estudo da língua italiana por intermédio de uma dinâmica de representação dos costumes alimentares motiva os participantes buscarem a inserção na cultura do país e desenvolvimento dos próprios valores identitários.

É importante considerar que outros rituais de consumo hedônico são realizados pelo grupo durante o ensino da língua. Um dos convidados, durante conversa informal no almoço, relatou que os alunos já participaram com a professora de outros eventos, não ligados diretamente à gastronomia, em que lhes eram apresentadas manifestações culturais com valor de representatividade étnica dos italianos.

"Eu não fui a todos, mas sei que ela leva os alunos para assistir exposição, shows, filmes...Há outros encontros, não é só esse aqui na casa dela". (Depoimento do convidado Lucas, em conversa informal com os autores).

Foi possível perceber no discurso da organizadora do almoço a exposição de seu "eu" social com forte caráter de "italianidade", influenciado pelas suas relações com a família, a música, a língua e a comida. Como descendente de italianos, a anfitriã sempre esteve em contato com os referidos tópicos, os quais a língua e a música impulsionaram sua escolha profissional, em primeiro lugar, e o aprofundamento nos costumes italianos a fez reconhecer a comida como elemento chave da 
identidade cultural. Abaixo, trechos de conversas informais com a anfitriã durante a observação são apresentados para corroborar com esses apontamentos:

"Pela minha origem, minha mãe e minhas avós (...) minha avó cantava ópera, misturava o português com o italiano. Essas coisas acabam ficando dentro da gente. Então, eu resolvi fazer Letras e ficar como professora. (...). E não há como você falar de língua italiana sem falar de comida, de música, de ópera, de amizade e encontro...

Por outro lado, sob a perspectiva dos convidados participantes, percebe-se um direcionamento para o reconhecimento da identidade cultural italiana e a tentativa de incorporação das significações simbólicas a ela atribuídas na construção do self. Um dos alunos presentes exemplifica esse contexto quando afirma que busca no curso uma forma de se preparar para vivenciar novamente uma experiência no país.

"Eu já passei um tempo lá [Itália] e agora eu continuo no curso para poder aprender mais, enquanto eu ainda não posso voltar". (Convidado Bruno em conversa com os participantes do evento).

Os alunos que aceitaram o convite do evento formaram um grupo com interesses específicos de busca por elementos de reforço à identidade social (Belk, 1988; Ahuvia, 2005; Bauman, 2005; Jenkins, 2014). Por se tratar de uma ação extra didática, portanto, nem todos os alunos da professora tiveram a motivação de participar. Aqueles reunidos no encontro constituíram um grupo de indivíduos que compartilha valores similares e se esforça para reunir aspectos de uma identidade comum, ainda que por influências distintas.

\section{DISCUSSÃO}

No evento analisado nesta pesquisa, verificou-se que o encontro à mesa reproduzindo o típico almoço completo italiano carregava uma teia de significações e simbolismos que foram importantes para identificar características da construção da identidade social dos indivíduos participantes. Como afirma Montanari (2013b), os rituais de comensalidade se inserem em um contexto cultural de consumo em que a comida assume o papel central nas trocas dos referidos valores simbólicos e significações que permitem realizar a produção de sentido de cada prática, comportamento, ritos e, em alguns casos, produzem sentido para justificar determinado prato e seus contornos. Quando se assume que o consumo é um fenômeno social, além de econômico, considera-se que suas práticas estão inseridas no ambiente cultural dos consumidores e irão, portanto, acontecer em função dos valores presentes em suas culturas e moldarão seu comportamento de modo contribuir no processo de construção de identidade social (Belk, 1988; McCracken, 1988; Barbosa, 2004; Ahuvia, 2005; Arnould \& Thompson, 2005).

O pranzo completo analisado foi um ritual de consumo que influenciou a identidade social dos participantes em duas perspectivas. A primeira diz respeito à professora organizadora do evento, que buscava reconstruir e preservar o self italiano por conta da sua ascendência familiar e do ensino da língua de modo que consiga inserir os alunos nas questões culturais italianas. Por meio da anfitriã, é possível visualizar a importância das experiências efetivas de imersão nos costumes para a manutenção da italianidade como aspecto identitário. A outra perspectiva de construção de identidade se dá sob a ótica dos alunos participantes do evento. Apesar de inicialmente possuírem motivações distintas para a busca do aprendizado da língua italiana, os valores individuais dos discentes participantes da experiência analisada convergem para o mesmo ponto de entusiasmo com a possibilidade de vivência de uma cultura diferente, cujo contato primário se deu em experiências de convívio em família, quando descendentes de italianos, ou a possibilidade de visitas e moradia temporária na Itália. Esses alunos incorporam valores da cultura italiana por meio das experiências de imersão proporcionadas pela professora, que, nesse contexto, veio a se tornar uma das referências de suas redes de associação pessoal. 
Laverty (2003) defende que o melhor caminho para um processo analítico é envolver o que chamou de co-construção dos dados. Isso significa trabalhar as informações coletadas nas entrevistas e nos outros meios, passando pelo círculo hermenêutico para se chegar à compreensão do fenômeno. 0 processo de construção do conhecimento percorrido neste estudo permitiu sistematizar os achados em quadro teórico esboçado em forma de diagrama, representado a seguir na Figura 1.

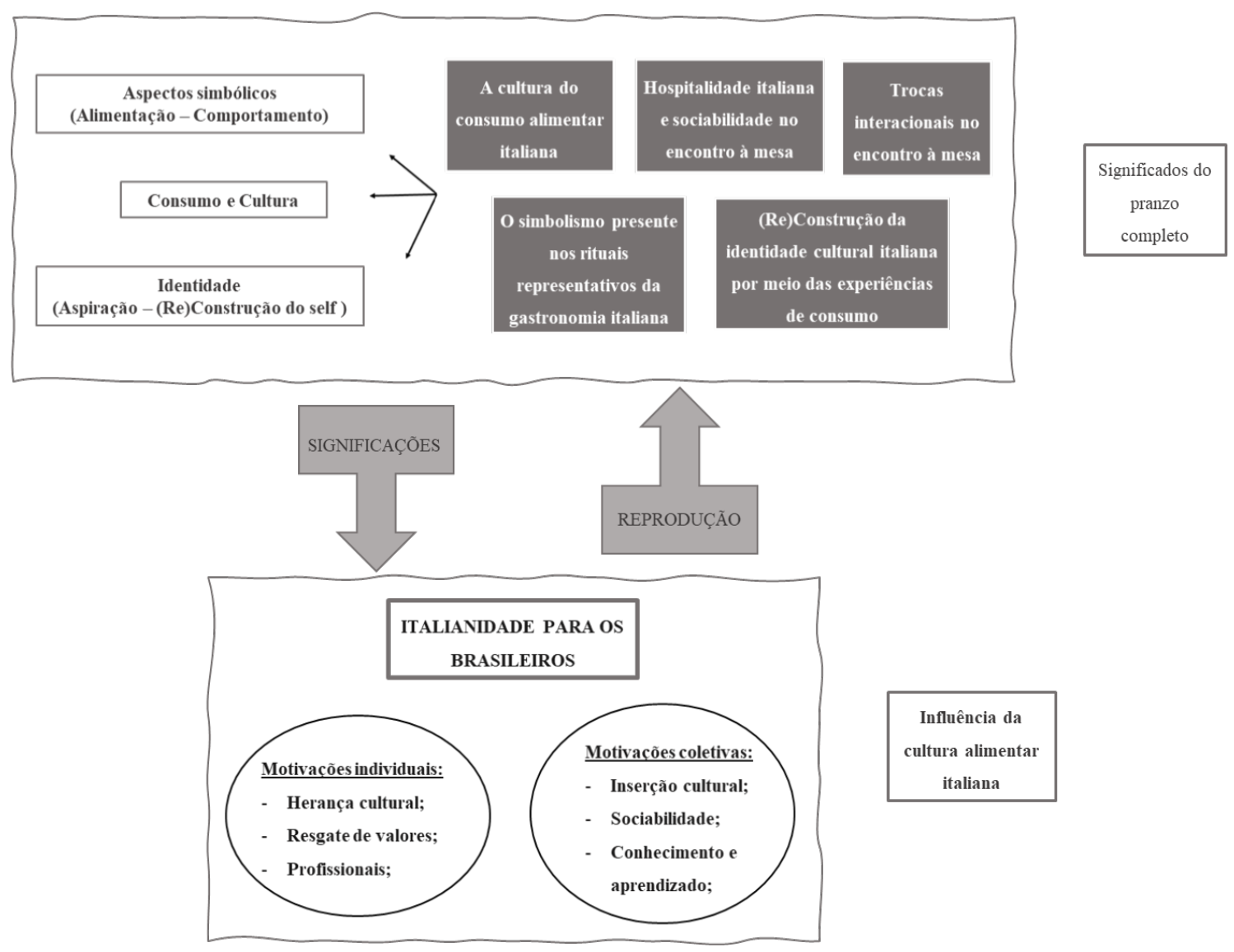

Fonte: Modelo teórico construídos com os dados emergentes da pesquisa em forma de diagrama confeccionado pelos autores.

Figura 1. Processo de Construção da Italianidade para os Brasileiros

O quadro teórico expressa o processo de construção do conhecimento mostrando a formação da italianidade para os brasileiros do grupo estudado, bastante influenciada pelos hábitos alimentares. 0 processo de significação do evento pelos convidados e pela anfitriã abrange o simbolismo presente na alimentação e no comportamento interacional, permitindo observar que o ritual do pranzo é fruto de uma articulação entre consumo e cultura que implica na (Re)construção do self. Esse processo é identificado pelo pesquisador e se evidencia na forma das categorias nativas estruturantes emergentes da pesquisa.

A representação na Figura 1 dos achados nesta pesquisa permite uma maior compreensão de como essas categorias estruturantes emergem como o resultado da análise dos discursos nativos e da observação dos comportamentos dos participantes do almoço. Cada uma delas foram identificadas como resultado de uma interpretação da perspectiva que os convidados têm sobre o evento, apresentando significações que se associam aos três pontos destacados no parágrafo anterior (aspectos simbólicos; consumo e cultura; identidade). As significações, quando reunidas, formam o conceito de identidade italiana, ou italianidade, para os brasileiros do grupo estudado.

Nesse sentido, a italianidade aparece neste contexto como uma composição: dos hábitos de consumo alimentar e seu sistema de normas expressos em comportamentos rituais (categoria 1); do 
estímulo ao encontro, à comensalidade e o esforço empregado para tal (categoria 2); as formas de interação identificadas pelo grupo como típicas da cultura italiana (categoria 3); o reconhecimento da refeição como símbolo de expressão cultural e de espaço para o convívio (categoria 4); e o consumo da gastronomia italiana em si como forma de construir uma identidade que abrange os demais aspectos (categoria 5). Não obstante, essas categorias nativas auxiliam também na investigação do processo de formação identitária ao permitir reconhecer as significações presentes em um contexto de motivações individuais e coletivas.

A italianidade surge em um contexto influenciado principalmente pelas características da cultura alimentar da Itália reconhecidas e compartilhadas pelos participantes. Quando reproduzida no evento do almoço completo, pode ser, portando, aprofundadas e mais bem analisada sob a forma das categorias de análise que emergem do processo de estudo.

É importante destacar, finalmente, que essa identidade cultural representada como italianidade é reconhecida a partir da prática de consumo da cozinha italiana e este consumo se dá por conta de motivações individuais, mais relacionadas à reconstrução do self, e de motivações coletivas, essas mais relacionadas a um processo entusiasta ou de aspiração em se inserir na cultura do país em questão.

A maior parte da literatura consultada mostra os aspectos da identidade cultural italiana de forma semelhante ao ponto de vista apresentado pela organizadora da experiência, visto que abordam a identidade social como reflexo do esforço da manutenção e preservação dos costumes italianos por grupos em colônias de imigrantes, principalmente provenientes do ambiente rural italiano. Porém, vale ressaltar que alguns valores distintos também são mencionados, tais como o apego ao trabalho com a lavoura, à unidade familiar e às tradições alimentares como expressão de sua italianidade. Este trabalho, no entanto, apresenta um arranjo a mais ao tratar da perspectiva de quem busca conhecer melhor a cultura italiana ou se inserir nela seguindo as próprias aspirações pessoais.

As diversas adaptações identificadas no evento, no que se refere à escolha das preparações, arranjo, disposição e a permanência dos convidados à mesa, não influenciam nas significações atribuídas pelos participantes. Cabe apontar, entretanto, que tais adaptações ocorrem em eventos fora da Itália e se configuram como distinções dos costumes italianos presentes em reuniões no país nativo (Helstosky, 2004; Cinotto, 2019; Counihan, 2019).

\section{CONCLUSÃO}

O consumo alimentar dos italianos carrega significações que dizem respeito à hospitalidade, confraternização e interação calorosa. Os rituais festivos, encontros familiares e entre amigos apresentam características semelhantes que extrapolam, inclusive, ao ambiente de serviços. Assim, os rituais de consumo da gastronomia italiana fora do país de origem obedecem a alguns desses critérios, enquanto se adaptam a outros. 0 consumo pode ocorrer a partir de motivações distintas, individuais ou coletivas, tais como tentativa de resgate ou manutenção da cultura, influências familiares, curiosidade e entusiasmo para o consumo hedônico. Essas motivações revelam aspectos do comportamento dos consumidores. Com isso em vista, verificou-se que existe um campo promissor para os estudos sobre a cultura italiana no Brasil articulados ao debate entre consumo e cultura, perpassando os assuntos que dizem respeito ao comportamento do consumidor, inclusive o processo de formação identitária.

Ao investigar um movimento de reprodução do almoço completo italiano (pranzo completo) realizado no contexto brasileiro, foi possível compreender as motivações envolvidas e a forma como isso reflete no "eu social", ou self, do consumidor. A análise dos dados coletados permitiu que emergissem cinco categorias estruturantes de significação nativas do evento. Estas versam sobre a cultura alimentar dos italianos, a hospitalidade no encontro à mesa, as trocas interacionais nos rituais de alimentação, o simbolismo presente nesses rituais e como se dá a construção ou reconstrução da identidade social em busca de preservar e se integrar na italianidade.

0 processo de construção do self foi abordado nesta pesquisa sob duas perspectivas. Do ponto de vista da professora anfitriã, a ascendência familiar e a relação profissional em torno do idioma são motivações fundantes para almejar a construção e manutenção do selfitaliano e, assim, lançar esforços 
para preservar a cultura italiana no ambiente a sua volta com dinâmicas inovadoras de ensino. Já na perspectiva dos alunos, as motivações pessoais se agrupam e acabam por se tornarem um conjunto de motivações coletivas que culmina na formação de um subgrupo de consumo. Tal subgrupo busca se inserir na cultura italiana por meio do idioma e dos principais símbolos culturais, entre eles se destaca a gastronomia.

Espera-se que, apesar das limitações, esta pesquisa traga subsídios aos pesquisadores acadêmicos de estudos do consumo e alimentação, além de identificar novas oportunidades de estudo. Ressalta-se aqui que dentre as limitações, a falta de entrevistas em profundidade com os demais convidados pode ser uma das mais relevantes por conta de não se permitir explorar mais a fundo o processo de significação do pranzo completo na perspectiva dos alunos; algo que poderia enriquecer o debate acerca das motivações pessoais e coletivas para as práticas de consumo no grupo estudado.

Contudo, o artigo apresenta contribuições teóricas ao estudo do tema, pois reflete sobre a percepção de que o consumo da gastronomia italiana, bem como o comportamento desse consumidor, pode estar associado a motivações que vão além da nostalgia, herança ou resgate cultural. A construção identitária do consumidor estudado, neste trabalho, está também relacionada a motivações sociais, profissionais e de expectativa com a inserção cultural, sociabilidade e aprendizado. Isso implica dizer que as experiências de consumo alimentar da cultura italiana evidenciam novos nuances dos aspectos desta subcultura de consumo no Brasil, e da formação identitária deste consumidor. Abrindo-se, assim, espaço para reflexão do tema e para novas pesquisas no assunto.

Para avançar na discussão dessa temática, sugere-se: a investigação de aspectos culturais de outras culinárias estrangeiras do ponto de vista científico, como as do sudeste asiático, a africana e a latino-americana, visando a identificar a ocorrência de novas motivações para o consumo alimentar dessas culturas. $\mathrm{Ou}$, em se tratando do aprofundamento das práticas de consumo da culinária italiana, pesquisas que investiguem as significações do consumo de produtos específicos, como o vinho italiano, os queijos e as massas, e suas implicações no comportamento do consumidor e na construção da identidade social e cultural.

\section{References}

Ahuvia, A. C. (2005). Beyond the extended self: loved objects and consumers' identity narratives. Journal of Consumer Research, 32(1), 171-184.

Albala, K. (2004). Italian Cuisine: A Cultural History by Alberto Capatti and Massimo Montanari. Translated by Aine O'Healy. Food, Culture \& Society, 7(1), 165-167.

Araujo, F.F., Bitar, N.P., Santos, M.M.A.S., Baião, M.R., \& Silva, T.C.P. (2019). Experiências de Consumo no Samba: Um estudo sobre o processo de significação da Feijoada Portelense. Revista Alceu, 20(38), 142-163.

Araujo, F.F., Cerchiaro, I.B., Silva, R.C.M., \& Espindola, R.S. (2020). Experience Marketing in Large Events: An Exploratory Study at Rio 2016 Olympic Games. International Journal of Development Research, v. 10, 36757-36765.

Araujo, F.F., \& Rocha, A. (2019). The redefining of later life through leisure: music and dance groups in Brazil. Leisure Studies, 38(5), 712-727, DOI: 10.1080/02614367.2019.1636847.

Araujo, F.F., Tonini, K.A.D., \& Estrella, T.B. (2018). Significação das Práticas do Consumo em Botecos Cariocas: Interação e Sociabilidade. Anais do XI ENEC - Encontro Nacional dos Estudos do Consumo. Rio de Janeiro, RJ, Brasil, 11.

Araujo, F. F., Turano, L. M., \& Vieira, F. C. (2019). Subculturas Religiosas de Consumo: Um estudo etnográfico de jovens católicos nas práticas dos Exercícios Espirituais. Consumer Behavior Review, 3(2), 99-119.

Arnould, E., \& Thompson, C. (2005). Consumer Culture Theory (CCT): Twenty Years of Research. Journal of Consumer Research, 31(4), 868-882.

Baccin, P., \& Azevedo, S. (2012). Mangiare all'italiana: Cozinha regional, cozinha nacional ou cozinha internacional? Revista Letras, 86(2). 
Significados do Almoço Completo Italiano: Articulações de consumo e cultura em uma experiência gastronômica em São Paulo

Barbosa, L. (2004). Sociedade de Consumo. Rio de Janeiro: Zahar.

Barbosa, L. (2007). Feijão com arroz e arroz com feijão: 0 Brasil no prato dos brasileiros. Horizontes Antropológicos, 13(28), 87-116.

Barbosa, L. (2010). Food and sociability on the contemporary Brazilian plate. Etnografica, 14(3), 567586.

Barbosa, L., \& Campbell, C. (2006). Cultura, consumo e identidade. FGV Editora.

Bauman, Z. (2005). Identidade: Entrevista concedida a Benedectto Vecchi. Rio de Janeiro: Zahar.

Belk, R.W. (1988). Possessions and the extended self. Journal of Consumer Research, 15(2), 139-168.

Benazzi, J. R. D. S. C. (2015, Setembro). Identidade e Comida: Uma Análise Das Sociabilidades e Encontros Interculturais na Festa de Nossa Senhora Achiropita-SP. Anais do XXXVIII Congresso Brasileiro de Ciências da Comunicação, Rio de Janeiro, RJ, Brasil.

Bertonha, J. F. (2013). Os italianos. (3 ${ }^{\underline{a}}$ ed.). São Paulo: Editora Contexto.

Bourdieu, P. (1979). La Distinction: critique sociale du jugement. Paris: Les Éditions de Minuit.

Boutaud, J. J. (2011). Comensalidade: Compartilhar a mesa. In A. Montandon. O livro da Hospitalidade: Acolhida do estrangeiro na história e nas culturas. São Paulo: SENAC.

Brown, S. (1997). Marketing Science in a Postmodern World: Introduction to the special issue. European Journal of Marketing, 31(3/4), 167-182.

Camargo, L. O. L. (2004). Hospitalidade. São Paulo: Alep.

Capatti, A., \& Montanari, M. (2003). Italian cuisine: a cultural history. Nova York: Columbia University Press.

Castro, H. C., Maciel, M. E., \& Maciel, R. A. (2016). Comida, cultura e identidade: conexões a partir do campo da gastronomia. Ágora, 18(1), 18-27.

Chakravarti, A., \& Janiszewski, C. (2003). The influence of macro-level motives on consideration set composition in novel purchase situations. Journal of Consumer Research, 30(2), 244-258.

Cinotto, S. (2019) Italian Diasporic Identities and Food. In R. SASSATELI (Ed). Italians and Food (p. 4370). Cham, Suíça: Palgrave Macmillan.

Collaço, J. H. L. (2012). Imigração e cozinha italiana na cidade de São Paulo. Concepções de fartura e distinção. Anuário Antropológico, (I), 211-236.

Corrêa, N. A. F., Cardoso, L. F. C., \& Silva, H. P. (2020). Comida de quilombo na merenda escolar: interfaces entre a cultura alimentar e o Programa Nacional de Alimentação Escolar. AmazônicaRevista de Antropologia, 12(1), 145-163.

Counihan, C. (2019). Food Consumption and Food Activism in Italy. In R. SASSATELI (Ed). Italians and Food (p. 101-125). Cham, Suíça: Palgrave Macmillan.

Da Matta, R. (2004). O que é o Brasil?. Rio de Janeiro: Rocco.

De Ruggiero, A. (2018). A saudade dos sabores e o comércio étnico dos imigrantes italianos no Brasil (1875-1914). Revista Prâksis, 1, 121-138.

Fantineli, D. G., \& Becker, E. L. S. (2011). A gastronomia italiana como atrativo turístico na região da Quarta Colônia, Rio Grande do Sul, Brasil. Disciplinarum Scientia, 12(1), 59-70.

Ferreira, V. A., \& Magalhães, R. (2011). Práticas alimentares cotidianas de mulheres obesas moradoras da Favela da Rocinha (Rio de Janeiro, RJ, Brasil). Ciência \& Saúde Coletiva, 16, 2983-2991.

Fischler, C. (1995). El (h)omnívoro. El gusto, la cocina y el cuerpo. Barcelona: Anagrama.

Fonseca, L., \& Camargo, L. O. L. (2013). Hospitalidade, migração e gastronomia: A família Marino e o Restaurante Carlino. CULTUR: Revista de Cultura e Turismo, 7(1), 47-65.

Helstosky, C. (2003). Recipe for the Nation: Reading Italian History through La scienza in cucina and La cucina futurista. Food and Foodways, 11(2-3), 113-140.

Helstosky, C. (2004). Garlic and oil: Food and politics in Italy. Oxford: Berg.

Hirschman, E. C., \& Holbrook, M. B. (1992) Postmodern consumer research: the study of consumption as text. California: Sage Publications.Holt, D. B. (2002). Why do brands cause trouble? A dialectical theory of consumer culture and branding. Journal of consumer research, 29(1), 70-90.

Jayne, J. M., Frongillo, E. A., Torres-McGehee, T. M., Emerson, D. M., Glover, S. H., \& Blake, C. E. (2018). A healthy eating identity is associated with healthier food choice behaviors among US Army soldiers. Military medicine, 183(11-12), 666-670.

Jenkins, R. (2014). Social identity (4⿳亠丷厂 ed). Nova York: Routledge. 
Joseph, D., \& Southcott, J. (2019). Meanings of leisure for older people: an Australian study of line dancing. Leisure Studies, 38(1), 74-87.

Jurado, A. T. C. (2016). The culinary and social-semiotic meaning of food: Spicy meals and their significance in Mexico, Italy, and Texas. Semiotica, 2016(211), 247-269.

Kotler, P., \& Keller, K. L. (2012). Administração de Marketing: análise, planejamento, implementação e controle (14aㅡ ed). São Paulo: Pearson Prentice Hall.

Lashley, C., Morrison, A., \& Randall, S. (2004). My most memorable meal ever! Hospitality as an emotional experience. Culinary taste, 165-184.

Laverty, S. M. (2003). Hermeneutic phenomenology and phenomenology: A comparison of historical and methodological considerations. International journal of qualitative methods, 2(3), 21-35.

Leoni, C. (2016). Italianidade amorosa e hospitaleira na gastronomia paulistana. Revista Fólio Comunicação e Turismo, 1, 83-93.

Lynch, P. A. (2005). Reflections on the home setting in hospitality. Journal of Hospitality and Tourism Management, 12(1), 37-50.

Machado, C. J. B., Menasche, R., \& Salamoni, G. (2015). Comida, identidade e simbolismo: saberes e práticas alimentares na conformação da italianidade na colônia de Pelotas. In R. Menasche (Org.). Saberes e sabores da colônia: alimentação e cultura como abordagem para o estudo do rural (p. 115-132). Porto Alegre: Ed. da UFRGS.

Maciel, M. E. (2001). Cultura e alimentação ou o que têm a ver os macaquinhos de Koshima com Brillat-Savarin? Horizontes antropológicos, 7(16), 145-156.

Manfio, J. M. (2017). As Crônicas da Colonização: a produção literária sobre a imigração italiana na região da quarta colônia - 1975. Acta Scientiarum. Human and Social Sciences, 39(1), 71-76.

Manfio, J. M. (2019). As comemorações do centenário da imigração italiana (colônia Silveira Martins, 1975-1993): a construção da identidade étnica através da comida. Ágora, 21(1), 66-73.

Mariani, J. F. (2011). How Italian food conquered the world. Nova York: Palgrave MacMillan.

McCracken, G. D. (1987). The history of consumption: a literature review and consumer guide. Journal of Consumer Policy, 10(2), 139-166.

McCracken, G. D. (1988). Culture and consumption: New approaches to the symbolic character of consumer goods and activities. Bloomington: Indiana University Press.

McFerran, B., Dahl, D. W., Fitzsimons, G. J., \& Morales, A. C. (2010). I'll have what she is having: effects of social influence and body type on the food choices of others. Journal of Consumer Research, 36, 915-929.

Moffat, T., Mohammed, C., \& Newbold, K. B. (2017). Cultural dimensions of food insecurity among immigrants and refugees. Human Organization, 76(1), 15-27.

Molinario, E., Lorenzi, C., Bartoccioni, F., Perucchini, P., Bobeth, S., Colléony, A., ... \& Richter, I. (2020). From childhood nature experiences to adult pro-environmental behaviors: An explanatory model of sustainable food consumption. Environmental Education Research, 26(8), 1137-1163.

Montanari, M. (2013a). Italian Identity in the Kitchen, or Food and the Nation. Nova York: Columbia University Press.

Montanari, M. (2013b). Comida como cultura. 2ª edição. São Paulo: Senac.

Monteleone, E., \& Dinnella, C. (2009). Italian meals. In: Meals in Science and Practice (p. 359-376). Woodhead Publishing.

Oliveira, F. A. M. (2006). Padrões alimentares em mudança: a cozinha italiana no interior paulista. Revista Brasileira de História, 26(51), 47-62.

Oliveira, N., \& Casqueiro, A. S. (2008). Ritos de comensalidade festiva na Bahia. In M.C.S. Freitas, G.A.V.

Fontes, N., \& Oliveira (org). Escritas e narrativas sobre alimentação e cultura (p. 55 - 88). Salvador: EDUFBA.

Parasecoli, F. (2014). Food, identity, and cultural reproduction in immigrant communities. Social Research: An International Quarterly, 81(2), 415-439.

Parasecoli, F. (2019). The Invention of Authentic Italian Food: Narratives, Rhetoric, and Media. In R. SASSATELI (Ed). Italians and Food (p. 17-41). Cham, Suíça: Palgrave Macmillan.

Peres, E. P. (2011). Aspectos da imigração italiana no Espírito Santo: a língua e cultura do Vêneto em Araguaia. Dimensões, (26), 44-59. 
Perini, K. P., \& Gastal, S. (2017). Italianidade como herança cultural: A gastronomia de imigração na região turística da Serra Gaúcha. Revista Turismo: estudos e práticas, 6, 78-100.

Portilho, F. (2020). Ativismo alimentar e consumo político-Duas gerações de ativismo alimentar no Brasil. Redes (St. Cruz Sul, Online), 25(2), 12-33.

Rabbiosi, C. (2019). Locating Italianicity Through Food and Tourism: Playing with Geographical Associations. In R. SASSATELI (Ed). Italians and Food (p. 71-100). Cham, Suíça: Palgrave Macmillan.

Rustomgy, V. L. S., \& Bastos, S. R. (2020). Para Além do Comércio de Comida Tradicional: 0 Empreendedorismo Étnico de Refugiados [São Paulo-SP, Brasil]. ROSA DOS VENTOS-Turismo e Hospitalidade, 12(4).

Santos, M. O., \& Zanini, M. C. (2008). Comida e simbolismo entre imigrantes italianos no Rio Grande do Sul (Brasil). Caderno Espaço Feminino, 19(1), 255-284.

Sassatelli, R. (2019). Introduction: Food, Foodways and Italianicity. In R. Sassateli (Ed). Italians and Food (p. 1-15). Cham, Suíça: Palgrave Macmillan.

Sauerbronn, J. F. R., Teixeira, C. D. S., \& Lodi, M. D. D. F. (2019). Saúde, estética e eficiência: relações entre práticas de consumo de alimentos as mulheres e seus corpos. Cadernos EBAPE. BR, 17(2), 389-402.

Schouten, J. W., \& McAlexander, J. H. (1995). Subcultures of consumption: An ethnography of the new bikers. Journal of consumer research, 22(1), 43-61.

Seidman, I. (1998). Interviewing as qualitative research. New York: Teachers College Press.

Sert, A. N. (2017). Italian Cuisine: Characteristics and Effects. Journal of Business Management and Economic Research, 1(1), 49-57.

Sieri, S., Agudo, A., Kesse, E., Klipstein-Grobusch, K., San-José, B., Welch, A., ... \& Slimani, N. (2002). Patterns of alcohol consumption in 10 European countries participating in the European Prospective Investigation into Cancer and Nutrition (EPIC) project. Public Health Nutrition, 5(6b), 1287-1296. DOI: 10.1079/PHN2002405

Silva, G. M. M., \& Confortin, H. (2015). Cultura italiana: estudo comparativo-descritivo da culinária italiana da Itália e da culinária italiana do Brasil. Perspectiva, 39(148), 33-45.

Solomon, M. R. (2016). Comportamento do consumidor: Comprando, possuindo e sendo (11 $\underline{\text { a }}$ ed). Porto Alegre: Bookman.

Spradley, J. P. (1979). The ethnographic interview. Belmont, CA: Wadsworth Group \& Thomson Learning.

Stacey, M. (1977). Methods of social research. Oxford: Pergamon Press.

Strauss, A., \& Corbin, J. (2008). Pesquisa Qualitativa: técnicas e procedimentos para o desenvolvimento de teoria fundamentada. Porto Alegre: Artmed.

Thompson, C. J. (1997). Interpreting Consumers: A hermeneutical framework for deriving marketing insights from the texts of consumers' consumption stories. Journal of Marketing Research, 34(4), 438-455.

Tureta, C., \& Alcadipani, R. (2011). Entre o Observador e o Integrante da Escola de Samba: os NãoHumanos e as Transformações Durante uma Pesquisa de Campo. RAC - Revista de Administração Contemporânea, 15(2), 71-78.

Vendrame, M. I. (2018). O "paraíso terrestre": alimentação como propaganda e construção da identidade italiana no sul do Brasil. Revista Brasileira de História \& Ciências Sociais, 10(20).

Yen, D. A. W., Cappellini, B., Wang, C. L., \& Nguyen, B. (2018). Food consumption when travelling abroad: Young Chinese sojourners' food consumption in the UK. Appetite, 121, 198-206.

Zanelato, R. N., \& Da Mota, R. R. (2014). A arte na gastronomia dos descendentes italianos na (região de tubarão) no Sul de Santa Catarina. Cadernos Acadêmicos, 6(1), 88-102.

Zanini, M. C. C. (2007). Um olhar antropológico sobre fatos e memórias da imigração italiana. Mana, 13(2), 521-547. 